\title{
Reducing the impact of penetrating trauma in the UK: a project by young doctors to teach first responder skills to young offenders
}

\author{
N Rhead*, C Neary-Bremer, S Jackson, S Rhead, T Conley, DJ Lockey \\ From London Trauma Conference 2012 \\ London, UK. 4-7 December 2012
}

\section{Background}

Interpersonal violence is the third leading cause of death within the European Region (as defined by World Health Organisation (WHO)) [1]. To address this concern the World Health Assembly passed a resolution (WHA 49.25) [2] declaring violence to be a public health priority. Furthermore the assembly passed resolution (WHA 56.24) [3] in 2003 urging continued development of a sciencebased public health approach to prevention of youth violence.

The public health problem is also specifically present in England where in 2006/2007 National Health Service data shows that 5,720 people were admitted to hospital following "assault by sharp object"[4]. Of these 179 were aged under 16 and a further 752 were aged between 16 and 18. Analysing Home Office data Hall and Innes found that the most likely victims of violent crime are young men aged between 16 and 24. The risk of being a victim of violent crime in this cohort is $13.3 \%$, over four times higher than the average risk (3\%)[5].

Other features of high risk groups include; trauma recidivism, previous exposure to violence, fear of violence and social relationships with violent peers. Furthermore those young people who have previously been involved in delinquency and are known to the criminal system are significantly more likely to be participants in carrying and using a weapon[6].

\section{The StreetDoctors project}

In Liverpool, UK a novel prevention and intervention training scheme has been established to decrease the morbidity and mortality from interpersonal violence

\footnotetext{
* Correspondence: n.j.rhead@doctors.org.uk StreetDoctors, Liverpool, UK
}

amongst young people. The only public health intervention of its kind globally StreetDoctors utilises medical students to provide high risk young people with the skills, knowledge and confidence to manage victims in the minutes immediately following injury, concentrating mainly on haemorrhage control. They do so because young offenders have been identified as a high risk population who often witness penetrating trauma. Half of the young offenders taught by StreetDoctors in Liverpool 2011 had witnessed penetrating trauma in the community and $90 \%$ felt that learning basic haemorrhage control techniques was a necessary skill for them and their peer group. When comparing fatal and non-fatal stabbings in Edinburgh, Webb et al found that the "the presence of a bystander capable and willing to request emergency medical assistance" had a positive impact upon the chance of survival from a stab injury[7].

By explaining potential long term consequences of penetrating trauma such as colostomies and physical disability it is hoped that StreetDoctors has a strong injury prevention message. The main aim of the intervention project is however to create a reservoir of potential healthcare providers who, unlike healthcare professionals will be able to deliver care at the point of injury. This intervention essentially bridges the gap between injury and treatment to limit blood loss and aims to decrease associated morbidity and increase the chance of survival to hospital. StreetDoctors uses a careful and competitive recruitment process to build teams of 10-20 volunteer medical students and doctors in each local area. Recruitment is based on applicants' ability to communicate in an engaging, inspiring and non-judgemental way. Volunteers are trained by certified trainers in haemorrhage control, basic life support and child protection. Experienced volunteers oversee the development of new branches, 
supporting new volunteers and ensuring a high standard of teaching is delivered.

StreetDoctors teaching is clear, simple and interactive. Role plays, DVDs, visual demonstrations and practical skill sessions are utilised to ensure complex information is understood and is easily recalled during a time of high stress. To ensure that familiarity and continuity are encouraged the same volunteers teach a group of 6-10 young people at a local centre on weekday evenings. In the first session basic haemorrhage control is taught. The first session covers topics such as basic anatomy and physiology, short and long term consequences of penetrating trauma, how to call an ambulance and management of bleeding before professional help arrives. The second session a week later targets drug use and is entitled "What to do if someone collapses". This includes Cardiopulmonary Resuscitation (CPR) and the recovery position following a summary of the previous week's session. Each session takes approximately 90 minutes.

The teaching which started in 2007 in Liverpool, UK has been delivered to more than 1,500 young people across five cities including London and Manchester. In this short period and with funding of just $£ 3500$ StreetDoctors is already aware of three cases where teaching has been successfully utilised.

\section{The future of the project}

Penetrating trauma is a major public health concern amongst the majority of UK urban populations. StreetDoctors will therefore expand to all major UK cities which have a problem with youth violence within the next five years. Following expansion within the UK StreetDoctors believes that the training it provides is applicable to high risk young people globally and therefore expects to establish international collaboration and new projects.

The teaching model used by StreetDoctors and the concept of utilising young highly skilled professional students to teach is essential to the success of the training program. StreetDoctors believe that this teaching model can be used to develop training programs in other areas of public health where high risk young people are at risk. Of particular concern sexual health and young women's safety in gang culture and illicit drug use are two areas where StreetDoctors hope to develop an intervention in coming years.

Young people who are known to the criminal justice system are understandably a difficult cohort to study particularly when attempting follow up and establishing utilisation of the education provided by the project. Therefore StreetDoctors hope to develop a research model to combat this and determine long term impacts of teaching on attitudes and behaviour. In the short term StreetDoctors will evaluate skills retention following teaching through the use of survey and Objective
Structured Clinical Examination (OSCE) techniques. Finally it is planned that the impact of the teaching upon morbidity/length of hospital stay and mortality will be evaluated.

\section{Published: 28 May 2013}

\section{References}

1. World Health Organisation: European Report on Preventing Violence and Knife Crime among Young People. WHO: Denmark; 2010.

2. World Health Assembly resolution: WHA49.25. WHO: Geneva; 1996.

3. World Health Assembly resolution: WHA 56.24. WHO: Geneva; 2003.

4. Berman G: Knife Crime Statistics. House of Commons Library: London; 2009.

5. Hall P, Innes J: Violent and Sexual Crime. Home Office Statistical Bulletin (2010). Crime in England and Wales 2009/10 Home Office Statistics: London; 2010.

6. Hawkins D, et al: Predictors of Youth Violence. Office of Juvenile Justice and Delinquency Prevention: Maryland; 2000.

7. Webb $E_{\text {, et }}$ al: A comparison of fatal and non-fatal knife injuries in Edinburgh. Forensic Science International 1999, 25:179-87.

doi:10.1186/1757-7241-21-S1-A3

Cite this article as: Rhead et al:: Reducing the impact of penetrating trauma in the UK: a project by young doctors to teach first responder skills to young offenders. Scandinavian Journal of Trauma, Resuscitation and Emergency Medicine 2013 21(Suppl 1):A3.

\section{Submit your next manuscript to BioMed Central} and take full advantage of:

- Convenient online submission

- Thorough peer review

- No space constraints or color figure charges

- Immediate publication on acceptance

- Inclusion in PubMed, CAS, Scopus and Google Scholar

- Research which is freely available for redistribution

Submit your manuscript at www.biomedcentral.com/submit
C Biomed Central 